\title{
Association of Hair Manganese Level with Symptoms in Attention-Deficit/Hyperactivity Disorder
}

\author{
Dong-Won Shin', Eun-Ji Kim², Se-Won Lim¹, Young-Chul Shin'1, Kang-Seob Oh¹, and Eun-Jin Kim ${ }^{1} \bowtie$ \\ ${ }^{1}$ Department of Psychiatry, Kangbuk Samsung Hospital, Sungkyunkwan University School of Medicine, Seoul, Republic of Korea \\ ${ }^{2}$ Dr. Lee's Clinic, Seoul, Republic of Korea
}

Objective The study examined the association between hair manganese level and symptoms of attention-deficit/hyperactivity disorder (ADHD) in Korean children.

Methods Forty clinic-referred children with ADHD and 43 normal control children participated in this study. The participants were 6-15 years old and were mainly from the urban area of Seoul, Korea. ADHD was diagnosed using the Diagnostic and Statistical Manual of Mental Disorders, 4th edition and Kiddie-Schedule for Affective Disorders and Schizophrenia-Present and Lifetime Version-Korean Version. The severity and symptoms of ADHD was evaluated according to the ADHD Diagnostic System, and parent's Korean ADHD Rating Scale (K-ARS). All participants completed intelligence test and hair mineral analysis. We divided the data of hair Mn into two groups to determine whether a deficit or excess of $\mathrm{Mn}$ are associated with ADHD. Multiple logistic regression analyses were performed to identify hair manganese levels associated with ADHD, controlling for age, sex, and full scale intelligence quotient (IQ).

Results The proportion of abnormal range Mn group was significantly high in ADHD compared to controls. However, after statistical control for covariates including age and sex, abnormal range Mn group was significantly associated with ADHD (OR=6.40, 95\% $\mathrm{CI}=1.39-29.41, \mathrm{p}=0.017)$.

Conclusion The result of this study suggests that excess exposure or deficiency of Mn were associated with ADHD among children in Korea. Further investigation is needed to evaluate the effects of hair manganese levels on symptoms in ADHD.

Psychiatry Investig 2015;12(1):66-72

Key Words Attention-deficit/hyperactivity disorder, Hair, Manganese.

\section{INTRODUCTION}

Attention-deficit/hyperactivity disorder (ADHD) is one of the most common psychiatric disorders of childhood and adolescence. ${ }^{1}$ ADHD has a global prevalence of about $5 \%$. ADHD is characterized by symptoms of inattention, hyperactivity, and impulsivity. The impairment areas of childhood ADHD include academic and social dysfunction and skill deficits. ${ }^{2}$ Even though the etiology of ADHD is not known exactly, what is believed to predict persistence of ADHD in-

Received: October 30, 2013 Revised: December 27, 2013

Accepted: January 2, 2014 Available online: January 12, 2015

$\triangle$ Correspondence: Eun-Jin Kim, MD

Department of Psychiatry, Kangbuk Samsung Hospital, Sungkyunkwan University School of Medicine, 29 Saemunan-ro, Jongno-gu, Seoul 110-746, Republic of Korea

Tel: +82-2-2001-8537, Fax: +82-2-2001-2211, E-mail: revise79@hanmail.net

(a) This is an Open Access article distributed under the terms of the Creative Commons Attribution Non-Commercial License (http://creativecommons.org/licenses/by$\mathrm{nc} / 3.0$ ) which permits unrestricted non-commercial use, distribution, and reproduction in any medium, provided the original work is properly cited. cludes family history of ADHD, cormobid psychiatric disorder, and psychosocial adversity. ${ }^{3}$ Some evidence based on neurochemical, imaging, and genetic studies suggest dysregulation of catecholaminergic systems in ADHD. ${ }^{4}$

Necessary nutrients, such as trace minerals including manganese $(\mathrm{Mn})$, iron, zinc, iodine, selenium, copper, fluoride, and chromium, are associated with changes in neuronal function that can lead to adverse effects on behavior and learning. ${ }^{5}$ Specifically, $\mathrm{Mn}$ is an essential nutrient in human and animals. $\mathrm{Mn}$ is needed by children to support normal brain growth and development. ${ }^{6} \mathrm{Mn}$ is a naturally occurring element that constitutes approximately $0.1 \%$ of the earth's crust, and in present in low levels in water, food, and air. ${ }^{7}$ The main exposure to manganese is by eating food or Mn-containing nutritional supplements. ${ }^{8}$ Vegetarians who consume foods rich in Mn such as whole-grain cereals, green leafy vegetables and nuts, as well as heavy tea drinkers, may have a higher intake of Mn than the average person.,10 The amount of Mn ingested in drinking water is substantially lower than intake 
from food, generally considered to be $<1 \%$ although depending on the concentration of $\mathrm{Mn}$, this route of intake can rise to $20 \% .{ }^{11}$ Certain occupations like welding, mining, and working in a factory where steel is made may increase chances of being exposed to high levels of Mn. ${ }^{12,13}$ Furthermore, people who smoke tobacco or inhale second-hand smoke are exposed to high level of Mn, particularly for children who live in house where there are smokers. ${ }^{9} \mathrm{Mn}$ concentrations in the serum increase after 12 months of age, and $\mathrm{Mn}$ has been measured as an average of $1.4 \pm 1.25 \mu \mathrm{g} / \mathrm{L}$ in children aged 1 month to 18 years. ${ }^{14}$ Concentrations of $\mathrm{Mn}$ in food and drinking water may vary between different countries and geographic area. Also, few data are available that provide clear cut-offs for nontoxic levels of Mn. Based on the dietary information described by World Heath Organization, ${ }^{10}$ Schroeder et al., ${ }^{15}$ and National Research Council, ${ }^{16}$ Environmental Protection Agency (EPA) estimated that an intake for $10 \mathrm{mg} \mathrm{Mn}$ per day in the diet is safe for lifetime exposure. ${ }^{17}$ The US Food and Drug Administration, EPA, and Ministry of Environment of South Korea also recommends a concentration of $\mathrm{Mn}$ in drinking water not to exceed $0.05 \mathrm{mg} / \mathrm{L}^{7}$

Although $\mathrm{Mn}$ is an essential metal at low doses, excessive and chronic exposure to high doses has been associated with neurotoxicity. ${ }^{18} \mathrm{Mn}$ neurotoxicity is characterized by alterations in dopamine neurobiology of brain. The dopamine transporter (DAT) is affected by high Mn levels. ${ }^{19} \mathrm{ADHD}$ has also been linked to impaired dopaminergic functioning, so high Mn levels in children with ADHD reflects a similar neurotoxic effect. ${ }^{20}$ In developing children, high Mn exposure have been associated with behavioral disinhibition, ${ }^{21}$ hyperactive behavior, ${ }^{21}$ and diminished cognitive function, such as intelligence quotient (IQ), ${ }^{18,22-24}$ memory, ${ }^{24,25}$ school grades. ${ }^{25}$ The high blood concentration of Mn inversely affected attention ${ }^{8}$ and IQ scores, ${ }^{26}$ in studies on children living in community. Farias et al. assessed a group of children with ADHD and matched control children attending public school and reported elevated serum level of $\mathrm{Mn}$ in treatment-naive children with ADHD compared to normal controls. ${ }^{8}$ A cross-sectional study in a non-risk area found that in school-aged children, higher levels of $\mathrm{Mn}$ in blood samples were inversely associated with significantly lower scores on tests of verbal IQ and full-scale IQ. ${ }^{26}$ High levels of Mn have been found in the scalp hair of children with $\mathrm{ADHD}^{27}$ and elevated levels of $\mathrm{Mn}$ that influence the dopaminergic system and dopaminergic transmission is postulated to be involved in the etiology of ADHD. Presently, we investigated the association between excess or deficency of $\mathrm{Mn}$ in head hair and symptoms of ADHD in non-risk environmental Mn exposure. Unlike previous studies that examined associations between $\mathrm{ADHD}$ and Mn using only rating scales, our study raised the accuracy of ADHD di- agnosis using semistructured interview. We contrasted Mn levels in a group of children with ADHD and normal control in Korea.

\section{METHODS}

\section{Participants and diagnosis}

Forty clinic-referred children with ADHD and 43 normal control children participated in this study. Normal controls were recruited by advertisement. The participants were $6-15$ years old and were mainly recruited from the urban area of Seoul, Korea. ADHD was diagnosed using the Diagnostic and Statistical Manual of Mental disorders, 4th edition (DSMIV) and Kiddie-Schedule for Affective Disorders and Schizophrenia-Present and Lifetime Version-Korean Version (KSADS-PL-K). K-SADS-PL-K is a comprehensive measure of a variety of past and present pathological conditions, and is useful as a diagnostic interviewing tool for diagnosing major psychiatric disorders in child and adolescent psychiatry. This measure was performed for all subjects as well as their parents in an effort to evaluate psychiatric disorders comorbid with ADHD. We excluded children with comorbid psychiatric disorder, medical illness requiring medication, or with a prior history of taking ADHD medication. All tests were performed by highly trained and supervised psychiatrists. To evaluate the severity of ADHD symptoms, parent's Korean ADHD Rating Scale (K-ARS) was used. The ADHD diagnostic system (ADS) was also used to evaluate the severity of inattention and impulsivity. Full-scale intelligence quotient (IQ) was measured using the Weschsler Intelligence Scale for Children, 3rd edition (WISC-III) and hair mineral was analyzed. Written informed consent was obtained from the parents of the children after the purpose and process of the study were explained. The protocol of this study was approved by the Institutional Review Board at Kangbuk Samsung Hospital (Seoul, Korea).

\section{Measures}

\section{K-SADS-PL-K}

The K-SADS-PL (Present and Lifetime Version) ${ }^{28}$ has been used to assess the severity of symptoms as well as the present and lifetime status of 32 DSM-IV ${ }^{29}$ child and adolescent psychiatric disorders. In Korea, Kim et al. ${ }^{30}$ examined the validity and reliability of the K-SADS-PL-K for Korean children. Good to excellent validity and reliability was demonstrated in diagnosing major disorders in child and adolescent psychiatric patients, including $\mathrm{ADHD}$, oppositional defiant disorder, and tic disorder. 


\section{Korean version of Dupaul's ARS, parent and teacher version}

Developed by Dupaul, the ARS lists 18 symptoms of ADHD based on DSM-IV diagnostic criteria: nine for attention-deficit and nine for hyperactivity-impulsivity domains. ${ }^{31}$ The scale has been translated and standardized in Korean. ${ }^{32}$ The K-ARS parent and teacher forms are considered to have high validity and reliability. Internal constancy of K-ARS by age is $0.77-0.89$. In interrater reliability between parents and teachers, Pearson correlation coefficients are 0.31-0.97 and are statistically significant $(\mathrm{p}<0.01)$. Items are rated on a 4 -point scale ( $0=$ never or rarely, $3=$ very often) checked by teacher and parent.

\section{ADS}

ADS is a computerized continuous performance test that consists of visual-auditory stilmulation tests. ${ }^{33}$ In each modality, the targets and non-targets are presented in the form of auditory or visual stimuli, which takes 15 minutes to complete. The test is available for Korean children over 5 years of age. It consists of three sessions: early, middle, and late phases. ADS has four variables: omission errors, commission errors, response time, and response time variability. An omission error indicates that the subject did not respond to a target stimulus, with high scores reflecting inattention. ${ }^{34}$ A commission error indicates the subject made an incorrect response to the non-target. This measures impulsivity ${ }^{35}$ and inhibitory control. ${ }^{36}$ The response time (RT) score measures the amount of time between presentation of the target stimulus and a correct response. The standard deviation of the RT measures variability or inconsistency of attention. ${ }^{33}$ Scores are reported as ageadjusted T-scores. In our study, all subject performed the ADS at baseline of the study.

\section{WISC-III}

The WISC-III, ${ }^{37}$ which is suitable for children $\geq 6$ years of age, consists of five (or six, depending on administration) verbal subscales that together provide a Verbal IQ score and a similar number of performance subscales that together provide a Performance IQ.

\section{Hair sampling and analysis}

Mn exposure levels of both groups (ADHD and control) were similar because they are living in the same geographic area. Hair analysis was performed to evaluate the long term metal exposure and mineral level. For analysis of hair minerals, all participants were asked not to chemically process their hair (i.e., no dyeing, perms, or frosting) for at least 3 weeks prior to hair sample acquisition. Participants also refrained from using hair gels, oils, and hair creams before sampling.
Approximately $150 \mathrm{mg}$ of hair was obtained from the parietal region of the scalp using stainless steel scissors so as not to contaminate the samples with any metal. Hair samples were collected from the children with their parents accompanying them to reduce children's anxiety and to increase their cooperation. The only proximal portion (within $3.0 \mathrm{~cm}$ of the root) was acquired as the sample. The hair samples were not washed for the assays. The cut hair was placed directly into a clean hair specimen envelope normally provided by the laboratory and sealed with the envelope's glue flap. Hair samples were assayed by Trace Elements, Incoperated (Addison, TX, USA). Each sample was weighed, placed in a $50 \mathrm{~mL}$ acid-washed polyprophylene tube, and trace-metal grade $\mathrm{HNO}_{3}$ was added. After centrifuging for 5 minutes, hair sample was transferred into a CEM Mars 5 Plus Microwave Digestion apparatus. Samples were kept at $70^{\circ} \mathrm{C}$ for $20 \mathrm{~min}$ and then the temperature was gradually increased to $115^{\circ} \mathrm{C}$ over $15 \mathrm{~min}$. Content of each mineral was analyzed by inductively coupled plasma-mass spectrometry [ICP-MS using a Sciex Elan 6100 apparatus (Perkin-Elmer, TX, USA)].

\section{Statistical analyses}

Demographic and clinical variables were compared by Student's t-test for continuous variables and Chi-square test for categorical variables. The Mn concentration was natural log transformed to achieve normal distributions of the variables. We divided hair Mn level into two groups: normal range Mn group (0.10-1.30 ppm), and abnormal range Mn group $(<0.10 \mathrm{ppm}$ or $>1.30 \mathrm{ppm})$ to determine whether a lack or overload of $\mathrm{Mn}$ are associated with ADHD. ${ }^{38,39}$ Two multiple logistic regressions were performed to evaluate the association between Mn level and ADHD after adjusting confounding factors. In Model I, Mn was used as a categorical variable after controlling age, sex. And full scale IQ was additionally controlled in Model II. Statistical analysis was performed using SPSS statistical software, version 18.0 (SPSS, Chicago, IL, USA). The cut-off for statistical significance set at $\mathrm{p}<0.05$.

\section{RESULTS}

\section{Demographic characteristics of the subjects}

The subjects comprised 83 children. Ethnicity and language were homogenous in the study sample. The demographic and clinical characteristics of the ADHD group $(n=40)$ and the control group $(n=43)$ are presented in Table 1 . Children averaged 9.72 years of age (range, 5 to 15 years, median age 9.5 years), with no significant differences $(10.27 \pm 3.14$; control, 9.35 $\pm 2.95 ; \mathrm{ADHD}, \mathrm{t}=1.385, \mathrm{p}=0.170$ ) between the two groups. There was no statistically significant difference in birth weight ( $3.43 \pm 0.71$; control, $3.30 \pm 0.42$; $\mathrm{ADHD}, \mathrm{t}=0.882$, 


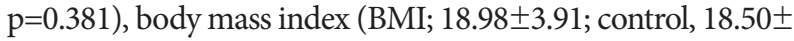
4.27; ADHD, $\mathrm{t}=0.480, \mathrm{p}=0.633$ ), sex distribution ( $83.7 \%$ for male; control, $85.0 \%$ for male; $\mathrm{ADHD}, \chi^{2}=0.026, \mathrm{p}=1.000$ ), education level of mother (77.5\% for $>12$ years; control, $57.9 \%$ for $>12$ years; $\mathrm{ADHD}, \chi^{2}=3.439, \mathrm{p}=0.090$ ), socioeconomic status ( $100 \%$ for middle; control, $5 \%$ for high, $90.2 \%$ for middle, $5 \%$ for low; ADHD, $\chi^{2}=3.565, \mathrm{p}=0.550$ ), and occupation of mother (29.3\% for housewife; control, $22.5 \%$ for housewife; $\mathrm{ADHD}, \chi^{2}=0.483, \mathrm{p}=0.861$ ) between the two groups.

\section{Comparison of clinical characteristics and hair Mn levels between ADHD and control groups}

The ADHD group had hair Mn concentrations that were slightly higher, but not statistically significant, than the control group (0.31 \pm 0.46 ; ADHD, $0.22 \pm 0.10$; control, $\mathrm{t}=0.255$, $\mathrm{p}=0.79$ ) (Table 2). Compared with the normal range $\mathrm{Mn}$ group, the abnormal range Mn group showed significantly high proportion of $\mathrm{ADHD}$ (42.9\% for $\mathrm{ADHD}$; normal range Mn group, $75.0 \%$ for ADHD; abnormal range $\mathrm{Mn}$ group, $\chi^{2}=4.244, \mathrm{p}=0.039$ ) (Table 2). Children in the ADHD group had a lower full scale IQ (112.39 \pm 10.44 ; control, 101.79 \pm 14.90 ; ADHD, $\mathrm{t}=3.199, \mathrm{p}=0.001)$, verbal IQ (116.00 \pm 10.40 ; control, 106.36 $\pm 15.48 ; \mathrm{ADHD}, \mathrm{t}=0.506, \mathrm{p}=0.002)$, and performance IQ (105.08 \pm 12.62 ; control, 96.28 \pm 14.47 ; ADHD, $\mathrm{t}=3.606$, $\mathrm{p}=0.006)$ than control children, with a significant difference between the two groups (Table 2). Total K-ARS were higher in children in the ADHD group compared to the control group, and was statistically significant (3.63 \pm 3.63 ; control,

Table 1. Sample summary statistics for ADHD and control: demographic variables

\begin{tabular}{lcccc}
\hline & $\begin{array}{c}\text { Control } \\
(\mathrm{N}=43)\end{array}$ & $\begin{array}{c}\text { ADHD } \\
(\mathrm{N}=40)\end{array}$ & t or $\chi^{2}$ & $\mathrm{p}$ \\
\hline Age (years) & $10.27 \pm 3.14$ & $9.35 \pm 2.95$ & 1.385 & $0.170^{*}$ \\
Birth weight & $3.43 \pm 0.71$ & $3.30 \pm 0.42$ & 0.882 & $0.381^{*}$ \\
BMI & $18.98 \pm 3.91$ & $18.50 \pm 4.27$ & 0.480 & $0.633^{*}$ \\
Male & $36(83.7 \%)$ & $34(85.0 \%)$ & 0.026 & $1.000^{\ddagger}$ \\
Education level of & $31(77.5 \%)$ & $22(57.9 \%)$ & 3.439 & $0.090^{\ddagger}$ \\
mothers (>12 years) & & & & \\
SES & & & 3.565 & $0.550^{\dagger}$ \\
$\quad$ High & $0(0 \%)$ & $2(5.0 \%)$ & & \\
$\quad$ Middle & $43(100 \%)$ & $36(90.0 \%)$ & & \\
$\quad$ Low & $0(0 \%)$ & $2(5.0 \%)$ & & \\
Occupation of mothers & & & 0.483 & $0.861^{\ddagger}$ \\
$\quad$ Housewife & $12(29.3 \%)$ & $9(22.5 \%)$ & & \\
\hline Data are exp & & & & \\
\hline
\end{tabular}

Data are expressed mean \pm standard deviation or $\mathrm{n}(\%)$. *statistical significance based on Student's t-test, ${ }^{\dagger}$ statistical significance based on Fisher's exact test, as appropriate, „statistical significance based on chi-square test, as appropriate. BMI: Body mass index, SES: socioeconomic status, ADHD: attention-deficit/hyperactivity disorder
28.37 $\pm 12.08 ; \mathrm{ADHD}, \mathrm{t}=-12.545, \mathrm{p}=0.000)($ Table 2$)$.

\section{Associations between hair Mn and ADHD}

Levels of hair Mn were significantly correlated with total KARS ( $r=0.275, p=0.013)$ and not significantly correlated with full scale IQ $(r=-0.036, p=0.755)$. Logistic regression analysis was performed to determine the influence of hair Mn levels on the prediction of ADHD. Hair Mn level was not significant association with ADHD after controlling age, sex, and full scale IQ ( $\mathrm{OR}=4.43,95 \% \mathrm{CI}=0.50-35.54, \mathrm{p}=0.178)$. Odds ratio of abnormal range $\mathrm{Mn}$ group was significantly high compared with the normal range $\mathrm{Mn}$ group after controlling age and sex in Model I (OR=6.40, 95\% CI=1.39-29.41, $\mathrm{p}=$ 0.017 ) (Table 3). The associations between abnormal range Mn group and ADHD were not significant after controlling age, sex, and full scale IQ in Model II (OR=2.60, 95\% CI= 0.45-15.16, $\mathrm{p}=0.289$ ) (Table 3).

\section{DISCUSSION}

The present study examined the association between concentrations of Mn in hair and ADHD symptoms of children. There was no difference between the ADHD group and control group in hair Mn levels. In logistic regression analysis using $\mathrm{Mn}$ as a continuous variable, odds ratio of $\mathrm{Mn}$ level was elevated without significant association with ADHD after controlling age, sex, and full scale IQ $(\mathrm{OR}=4.43,95 \% \mathrm{CI}=$ 0.50-35.54, $\mathrm{p}=0.178$ ). After statistical control for covariates including age and sex, abnormal range Mn group was signifi-

Table 2. Sample summary statistics for ADHD and control: KARS, ADS, IQ, and Mn level

\begin{tabular}{|c|c|c|c|c|}
\hline & Control & ADHD & t or $\chi^{2}$ & $\mathrm{p}$ \\
\hline K-ARS & $3.63 \pm 3.63$ & $28.37 \pm 12.08$ & $-12.545<$ & $<0.001$ \\
\hline Full scale IQ & $112.39 \pm 10.44$ & $101.79 \pm 14.90$ & 3.199 & 0.001 \\
\hline Verbal IQ & $116.00 \pm 10.40$ & $106.36 \pm 15.48$ & 0.506 & 0.002 \\
\hline Performance IQ & $105.08 \pm 12.62$ & $96.28 \pm 14.47$ & 3.606 & 0.006 \\
\hline $\mathrm{Mn}(\mathrm{ppm})$ & $0.22 \pm 0.10$ & $0.31 \pm 0.46$ & 0.255 & $0.800^{*}$ \\
\hline Mn group & & & 4.244 & $0.039^{\dagger}$ \\
\hline $\begin{array}{l}\text { Normal range } \\
\text { group }(0.10-1.30)\end{array}$ & $40(93 \%)$ & $30(76.9 \%)$ & & \\
\hline \multicolumn{5}{|c|}{ Abnormal range group } \\
\hline $\operatorname{High}(>1.30)$ & $0(0 \%)$ & $2(5.1 \%)$ & & \\
\hline Low $(<0.10)$ & $3(7 \%)$ & $7(17.9 \%)$ & & \\
\hline
\end{tabular}

Data are expressed mean \pm standard deviation or $\mathrm{n}(\%) .{ }^{*} \mathrm{Mn}$ concentrations was natural log transformed to achieve normal distributions of the variables, ${ }^{\dagger}$ statistical significance based on chi-square test as appropriate, using two categories of Mn were $0.10-1.30$ $\mathrm{ppm}$ and $<0.10 \mathrm{ppm}$ or $>1.30 \mathrm{ppm}$. K-ARS: Korean version of Dupaul's Attention-Deficit/Hyperactivity Disorder Rating Scale, IQ: intelligence quotient, ADHD: attention-deficit/hyperactivity disorder 
Table 3. Result of logistic regression analysis

\begin{tabular}{|c|c|c|c|c|}
\hline & \multicolumn{2}{|c|}{ Model I } & \multicolumn{2}{|c|}{ Model II } \\
\hline & AOR $(95 \% \mathrm{CI})$ & $\mathrm{p}$ & $\mathrm{AOR}(95 \% \mathrm{CI})$ & $\mathrm{p}$ \\
\hline \multicolumn{5}{|l|}{$\mathrm{Mn}(\mathrm{ppm})$} \\
\hline Normal range group & 1 (reference) & & 1 (reference) & \\
\hline Abnormal range group & $6.40(1.39-29.41)$ & 0.017 & $2.59(0.44-15.16)$ & 0.289 \\
\hline Age & $0.85(0.72-0.99)$ & 0.048 & $0.73(0.59-0.91)$ & 0.006 \\
\hline Sex & $0.60(0.16-2.24)$ & 0.450 & $0.98(0.21-4.54)$ & 0.987 \\
\hline Full scale IQ & & & $0.91(0.87-0.96)$ & 0.001 \\
\hline
\end{tabular}

Model I: adjusted for age and sex, Model II: adjusted for age, sex and full scale IQ. AOR (95\% CI): adjusted odds ratio and 95\% confidence interval, IQ: intelligence quotient

cantly associated with ADHD (OR=6.40, 95\% CI=1.3929.41, $\mathrm{p}=0.017$ ). A significant association was evident between Mn levels and the presence of ADHD.

Although the neurotoxicity of lead $(\mathrm{Pb})$ is well established, ${ }^{40}$ relatively little is known about $\mathrm{Mn}$ neurotoxicity. Unlike $\mathrm{Pb}$, which is a toxic metal, $\mathrm{Mn}$ is an essential microelement. ${ }^{41} \mathrm{Mn}$ is needed by infants and children to support normal growth and development of brain. ${ }^{6}$ There is no concensus on the optimal biomarkers of Mn exposure in children. ${ }^{42}$ In a small casecontrol study, children with ADHD had significantly higher hair Mn levels than did controls. ${ }^{27}$ In this regard, recent studies have observed the impacts of heavy metals on childhood cognition and behavior. Exposure to subtoxic levels of Mn has also been suggested to be associated learning and attention problems, ${ }^{43,44}$ hyperactive behavior, and learning problems, ${ }^{3}$ with neurofunctional alterations characterized by neuromotor and cognitive deficits, and mood changes. ${ }^{5}$ Recently, a series of studies reported associations between excessive Mn exposure and neurologic disorders in children, mainly behavioral effects. ${ }^{45} \mathrm{~A}$ number of studies reported relationships between excessive $\mathrm{Mn}$ exposure and neurobehavioral performance, ${ }^{25}$ lower learning and memory test scores, ${ }^{22,24}$ and cognitive attention deficits in children. ${ }^{46}$ We additionally showed the results after controlling full scale IQ. The associations between abnormal range Mn group and ADHD were not significant after adjusting age, sex, and full scale IQ in Model II ( $\mathrm{OR}=2.60$, $95 \% \mathrm{CI}=0.45-15.16, \mathrm{p}=0.289$ ). Previous study reported that $\mathrm{ADHD}$ is more likely to be present in the context of developmental delay, at the level of borderline-to-mild intellectual disability. ${ }^{47,48}$ In contrast, other study reported major impact of ADHD on lower IQ scores, impaired verbal and visuo-spatial short-term memory. ${ }^{49,50}$ Therefore, this finding after adjusting full scale IQ should be viewed with caution

Our study findings support the hypothesis that high-level, chronic exposure and deficiency of $\mathrm{Mn}$ is associated with $\mathrm{ADHD}$ risk in children. It is consistent with previous findings of an association between Mn hair level and ADHD. ${ }^{21,51,52}$ Compared with adults, infants and younger children can ab- sorb and accumulate more Mn. Homeostatic mechanisms that limit absoption of ingested $\mathrm{Mn}$ are not fully developed in infants and younger children, ${ }^{53}$ allowing Mn to more easily enter the brain. ${ }^{54}$

The study has several limitations. First, the small sample size limited our ability to evaluate and adjust for potential compounding factor. Because of small sample size, we combined groups with hair Mn level which lies less than $0.10 \mathrm{ppm}$ or greater than $1.30 \mathrm{ppm}$ and then defined it as an abnormal range $\mathrm{Mn}$ group. A recent study on relationship between blood $\mathrm{Mn}$ levels and child's attention, cognition, behavior and academic performance divided $\mathrm{Mn}$ level into three groups: lower, and upper 5th percentile and middle 90th percentile. ${ }^{52}$ They reported that excess or deficiency of Mn can cause harmful effects in children. Although we could not classify $\mathrm{Mn}$ into three groups due to small sample size, the results was not much different from the results of three groups. Also, small sample size leads to likelihood of detecting real associations between hair Mn levels and childhood ADHD was reduced. But, Mn concentration was completely dissociated from socioeconomic status, which reduces the potential for confounding. ${ }^{22}$ Second, the lack of other trace elements influence on the symptoms of ADHD in our study makes it difficult to conclude that manganese levels are specifically associated with ADHD symptoms. Third, the concentrations of Mn were measured in hair only. Several tests are used to measure $\mathrm{Mn}$ in blood, hair, urine, or feces. Currently, no consensus has emerged as to the optimal biomarker of exposure to manganese. ${ }^{42}$ Hair might not be the tissue that provides the most accurate measure of a child's exposure to the metals of interest. Also, it is unknown that hair accurately reflects Mn level of brain because the exact mechanism of $\mathrm{Mn}$ transport into the brain is not well understood. ${ }^{55}$ Although there have been several discussions about the usefulness of hair analysis and its standardization for studying Mn exposure, ${ }^{7}$ additional measures, such as serum $\mathrm{Mn}$, are needed. While urine and blood tend to show current exposure or recent body status, hair reflects chronic exposure and reveals retrospective information 
about an individual's nutritional status and exposure. ${ }^{56,57}$ Also, hair is easier and safer to collect, ship, and store for mineral analyses than blood or urine and the analysis is less expensive. ${ }^{58}$ Research suggests its usefulness as an early predictor of toxic exposure. ${ }^{7}$ For this reason, we decided trace element analysis in hair as a screening tool. But, use of hair is problematic for several reasons. For example, exogenous contamination may yield values that do not reflect absorbed does, and hair growth and loss limit its usefulness to only a few months after exposure. ${ }^{59}$ Other researches reported that manganese concentrations in hair vary with hair color. ${ }^{60}$ Forth, the crosssectional nature of our data makes it difficult to infer a causal relationship from the results.

In summary, this study revealed significant associations between hair Mn levels and ADHD after statistical control for covariates. Possible foci for future research should include prospective design, broadly representative ADHD samples, and good ethics of research. Further research is needed to understand the causal relationship between Mn exposure and children's health, and to enable an improved risk assessement.

\section{REFERENCES}

1. Polanczyk G, de Lima MS, Horta BL, Biederman J, Rohde LA. The worldwide prevalence of ADHD: a systematic review and metaregression analysis. Am J Psychiatry 2007;164:942-948.

2. Costello EJ, Mustillo S, Erkanli A, Keeler G, Angold A. Prevalence and development of psychiatric disorders in childhood and adolescence. Arch Gen Psychiatry 2003;60:837-844.

3. Biederman J, Milberger S, Faraone SV, Kiely K, Guite J, Mick E, et al. Family-environment risk factors for attention-deficit hyperactivity disorder. A test of Rutter's indicators of adversity. Arch Gen Psychiatry 1995;52:464-470.

4. Biederman J. Attention-deficit/hyperactivity disorder: a selective overview. Biol Psychiatry 2005;57:1215-1220.

5. Hubbs-Tait L, Nation JR, Krebs NF, Bellinger DC. Neurotoxicant, micronutrients and social environment: individual and combined effects on children's development. Psychol Sci Public Interest 2005;6:57-121.

6. Dorman DC, Struve MF, Clewell HJ 3rd, Andersen ME. Application of pharmacokinetic data to the risk assessment of inhaled manganese. Neurotoxicology 2006;27:752-764.

7. Williams M, Todd GD, Roney N, Crawford J, Coles C, McClure PR, et al. Toxicological Profile for Manganese. Atlanta, GA: Agency for Toxic Substances and Disease Registry; 2000.

8. Farias AC, Cunha A, Benko CR, McCracken JT, Costa MT, Farias LG, et al. Manganese in children with attention-deficit/hyperactivity disorder: relationship with methylphenidate exposure. J Child Adolesc Psychopharmacol 2010;20:113-118.

9. Williams M, Todd GD, Roney N, Crawford J, Coles C, McClure PR, et al. Toxicological Profile for Manganese. Atlanta GA: Agency for Toxic Substances and Disease Registry; 2012.

10. World Health Organization. Trace Elements in Human Nutrition: Manganese. Geneva, Switzerland: Technical Report Service 532 WHO Report of a WHO Expert Committee; 1973.

11. Loranger S, Zayed J. Environmental and occupational exposure to manganese: a multimedia assessment. Int Arch Occup Environ Health 1995;67:101-110.

12. Dobson AW, Erikson KM, Aschner M. Manganese neurotoxicity. Ann N Y Acad Sci 2004;1012:115-128.
13. Perl DP, Olanow CW. The neuropathology of manganese-induced Parkinsonism. J Neuropathol Exp Neurol 2007;66:675-682.

14. Rukgauer M, Klein J, Kruse-Jarres JD. Reference values for the trace elements copper, manganese, selenium, and zinc in the serum/plasma of children, adolescents, and adults. J Trace Elem Med Biol 1997;11:92-98.

15. Schroeder HA, Balassa JJ, Tipton IH. Essential trace metals in man: manganese. A study in homeostasis. J Chronic Dis 1966;19:545-571.

16. National Research Council, Board on Environmental Studies and Toxicology. Biologic Markers in Reproductive Toxicology. Washington DC: National Academy Press; 1989.

17. U.S. Environmental Protection Agency. Drinking Water Health Advisory for Manganese. Report 822R04003. Available at: http://www.epa. gov/safewater. Accessed October 24, 2013.

18. Wasserman GA, Liu X, Parvez F, Ahsan H, Levy D, Factor-Litvak P, et al. Water manganese exposure and children's intellectual function in Araihazar, Bangladesh. Environ Health Perspect 2006;114:124-129.

19. Anderson JG, Cooney PT, Erikson KM. Inhibition of DAT function attenuates manganese accumulation in the globus pallidus. Environ Toxicol Pharmacol 2007;23:179-184.

20. Tran TT, Chowanadisai W, Lonnerdal B, Le L, Parker M, Chicz-Demet A, et al. Effects of neonatal dietary manganese exposure on brain dopamine levels and neurocognitive functions. Neurotoxicology 2002;23: 645-651.

21. Bouchard M, Laforest F, Vandelac L, Bellinger D, Mergler D. Hair manganese and hyperactive behaviors: pilot study of school-age children exposed through tap water. Environ Health Perspect 2007;115:122-127.

22. Bouchard MF, Sauve S, Barbeau B, Legrand M, Brodeur ME, Bouffard $\mathrm{T}$, et al. Intellectual impairment in school-age children exposed to manganese from drinking water. Environ Health Perspect 2011;119:138143.

23. Menezes-Filho JA, Novaes Cde O, Moreira JC, Sarcinelli PN, Mergler D. Elevated manganese and cognitive performance in school-aged children and their mothers. Environ Res 2011;111:156-163.

24. Wright RO, Amarasiriwardena C, Woolf AD, Jim R, Bellinger DC. Neuropsychological correlates of hair arsenic, manganese, and cadmium levels in school-age children residing near a hazardous waste site. Neurotoxicology 2006;27:210-216.

25. He P, Liu DH, Zhang GQ. Effects of high-level-manganese sewage irrigation on children's neurobehavior. Zhonghua Yu Fang Yi Xue Za Zhi 1994;28:216-218.

26. Kim Y, Kim BN, Hong YC, Shin MS, Yoo HJ, Kim JW, et al. Co-exposure to environmental lead and manganese affects the intelligence of school-aged children. Neurotoxicology 2009;30:564-571.

27. Crinella FM, Cordova EJ, Ericson J. Manganese, aggression, and attention-deficit hyperactivity disorder. Neurotoxicology 1998;19:468-469.

28. Kaufman J, Birmaher B, Brent DA, Ryan ND, Rao U. K-SADS-PL. J Am Acad Child Adolesc Psychiatry 2000;39:1208.

29. American Psychiatric Association. Diagnostic and Statistical Manual of Mental Disorders: DSM-IV-TR. Washington DC: American Psychiatric Association; 2000.

30. Kim YS, Cheon KA, Kim BN, Chang SA, Yoo HJ, Kim JW, et al. The reliability and validity of Kiddie-Schedule for Affective Disorders and Schizophrenia-Present and Lifetime Version-Korean version (KSADS-PL-K). Yonsei Med J 2004;45:81-89.

31. DuPaul GJ. Parent and teacher ratings of ADHD symptom: psychometric properties in a community-based samples. J Clin Child Psychol 1991;20:245-253.

32. So YK, Noh JS, Kim YS, Ko SG, Koh YJ. The reliability and validity of Korean Parent and Teacher ADHD Rating Scale. J Korean Neuropsychiatr Assoc 2002;41:283-289.

33. Shin MS, Cho SC, Chun SY, Hong KE. A study of the development and standardization of ADHD diagnostic system. J Child Adolesc Psychiatry 2000 11:91-99.

34. Beck LH, Bransome ED Jr, Mirsky AF, Rosvold HE, Sarason I. A continuous performance test of brain damage. J Consult Psychol 1956; 
20:343-350.

35. Conners CK, Epstein JN, Angold A, Klaric J. Continuous performance test performance in a normative epidemiological sample. J Abnorm Child Psychol 2003;31:555-562.

36. Riccio CA, Waldrop JJ, Reynolds CR, Lowe P. Effects of stimulants on the continuous performance test (CPT): implications for CPT use and interpretation. J Neuropsychiatry Clin Neurosci 2001;13:326-335.

37. Wechsler D. Wechsler Scale for Infant Intelligence. San Antonio, TX: Psychological Corporation; 1991.

38. Kim G, Song HJ. Hair mineral analysis of normal Korean children. Korean J Dermatol 2002;40:1518-1526.

39. Wilson L. Nutritional balancing and hair tissue mineral analysis. Explore 2003;12:42-53.

40. Bellinger DC. Lead. Pediatrics 2004;113(4 Suppl):1016-1022.

41. McMillan DE. A brief history of the neurobehavioral toxicity of manganese: some unanswered questions. Neurotoxicology 1999;20:499507.

42. Smith D, Gwiazda R, Bowler R, Roels H, Park R, Taicher C, et al. Biomarkers of Mn exposure in humans. Am J Ind Med 2007;50:801-811.

43. Collipp PJ, Chen SY, Maitinsky S. Manganese in infant formulas and learning disability. Ann Nutr Metab 1983;27:488-494.

44. Pihl RO, Parkes M. Hair element content in learning disabled children. Science 1977;198:204-206.

45. Ljung K, Vahter M. Time to re-evaluate the guideline value for manganese in drinking water? Environ Health Perspect 2007;115:1533-1538.

46. Woolf A, Wright R, Amarasiriwardena C, Bellinger D. A child with chronic manganese exposure from drinking water. Environ Health Perspect 2002;110:613-616.

47. Voigt RG, Barbaresi WJ, Colligan RC, Weaver AL, Katusic SK. Developmental dissociation, deviance, and delay: occurrence of attentiondeficit-hyperactivity disorder in individuals with and without borderline-to-mild intellectual disability. Dev Med Child Neurol 2006;48:831835.

48. Frazier TW, Demaree HA, Youngstrom EA. Meta-analysis of intellectual and neuropsychological test performance in attention-deficit/hyperactivity disorder. Neuropsychology 2004;18:543-555.
49. Gau SS, Chiang HL. Association between early attention-deficit/hyperactivity symptoms and current verbal and visuo-spatial short-term memory. Res Dev Disabil 2013;34:710-720.

50. Seidman LJ, Biederman J, Monuteaux MC, Doyle AE, Faraone SV. Learning disabilities and executive dysfunction in boys with attentiondeficit/hyperactivity disorder. Neuropsychology 2001;15:544-556.

51. Yousef S, Adem A, Zoubeidi T, Kosanovic M, Mabrouk AA, Eapen V. Attention deficit hyperactivity disorder and environmental toxic metal exposure in the United Arab Emirates. J Trop Pediatr 2011;57:457-460.

52. Bhang SY, Cho SC, Kim JW, Hong YC, Shin MS, Yoo HJ, et al. Relationship between blood manganese levels and children's attention, cognition, behavior, and academic performance--a nationwide cross-sectional study. Environ Res 2013;126:9-16.

53. Winder BS. Manganese in the air: are children at greater risk than adults? J Toxicol Environ Health A 2010;73:156-158.

54. Dorner K, Dziadzka S, Hohn A, Sievers E, Oldigs HD, Schulz-Lell G, et al. Longitudinal manganese and copper balances in young infants and preterm infants fed on breast-milk and adapted cow's milk formulas. $\mathrm{Br}$ J Nutr 1989;61:559-572.

55. Tuschl K, Mills PB, Clayton PT. Manganese and the brain. Int Rev Neurobiol 2013;110:277-312.

56. Bass DA, Hickock D, Quig D, Urek K. Trace element analysis in hair: factors determining accuracy, precision, and reliability. Altern Med Rev 2001;6:472-481.

57. Emara EM, Imam H, Hassan MA, Elnaby SH. Biological application of laser induced breakdown spectroscopy technique for determination of trace elements in hair. Talanta 2013;117:176-183.

58. Druyan ME, Bass D, Puchyr R, Urek K, Quig D, Harmon E, et al. Determination of reference ranges for elements in human scalp hair. Biol Trace Elem Res 1998;62:183-197.

59. Stauber JL, Florence TM, Webster WS. The use of scalp hair to monitor manganese in aborigines from Groote Eylandt. Neurotoxicology 1987; 8:431-435.

60. Sturaro A, Parvoli G, Doretti L, Allegri G, Costa C. The influence of color, age, and sex on the content of zinc, copper, nickel, manganese, and lead in human hair. Biol Trace Elem Res 1994;40:1-8. 